\title{
A hybrid approach for integrated healthcare cooperative purchasing and supply chain configuration
}

\author{
Nazaré Rego ${ }^{1,2}$, João Claro ${ }^{2,3}$ and Jorge Pinho de Sousa ${ }^{2,3}$, \\ ${ }^{1}$ Escola de Economia e Gestão, Universidade do Minho, \\ Campus de Gualtar, 4710-057 Braga, Portugal \\ ${ }^{2}$ INESC TEC, \\ Rua Dr. Roberto Frias, 378, 4200 - 465 Porto, Portugal \\ ${ }^{3}$ Faculdade de Engenharia, Universidade do Porto, \\ Rua Dr. Roberto Frias, 378, 4200 - 465 Porto, Portugal
}

\begin{abstract}
This paper presents an innovative and flexible approach for recommending the number, size and composition of purchasing groups, for a set of hospitals willing to cooperate, while minimising their shared supply chain costs. This approach makes the financial impact of the various cooperation alternatives transparent to the group and the individual participants, opening way to a negotiation process concerning the allocation of the cooperation costs and gains. The approach was developed around a hybrid Variable Neighbourhood Search (VNS) / Tabu Search metaheuristic, resulting in a flexible tool that can be applied to purchasing groups with different characteristics, namely different operative and market circumstances, and to supply chains with different topologies and atypical cost characteristics. Preliminary computational results show the potential of the approach in solving a broad range of problems.
\end{abstract}

Keywords: purchasing groups, healthcare, Tabu Search, VNS

\section{Introduction}

In the last decades there has been, in most OECD countries, a continuous growth in health expenditures as a share of GDP (see some examples in Figure 1). Although this economic effort has been accompanied by significant improvements in health services (illustrated in Figure 1 by the evolution of Infant Mortality and Life Expectancy at Birth), there is a collective concern for control of costs and for systems efficiency.

In Portugal, hospitals are accountable for approximately $38 \%$ of total current expenditure on health, and more than $80 \%$ of it arises at public hospitals (i.e., hospitals included in the National Health Service, NHS) [1]. In 2010, 55\% of the 231 hospitals in 
the country were state owned and concentrated $73 \%$ of all hospital beds [2]. Seven hospital systems represent more than $50 \%$ of total pharmaceuticals consumption by publicly managed hospitals [3]. In 2009 the supply costs accounted for $30 \%$ to $40 \%$ of their operational costs ${ }^{1}$, which is in line with the proportion observed at US hospitals [4]. Pharmaceuticals represent between $70 \%$ and $80 \%$ of these supply costs while medical-surgical materials represent between $20 \%$ and $25 \%$.

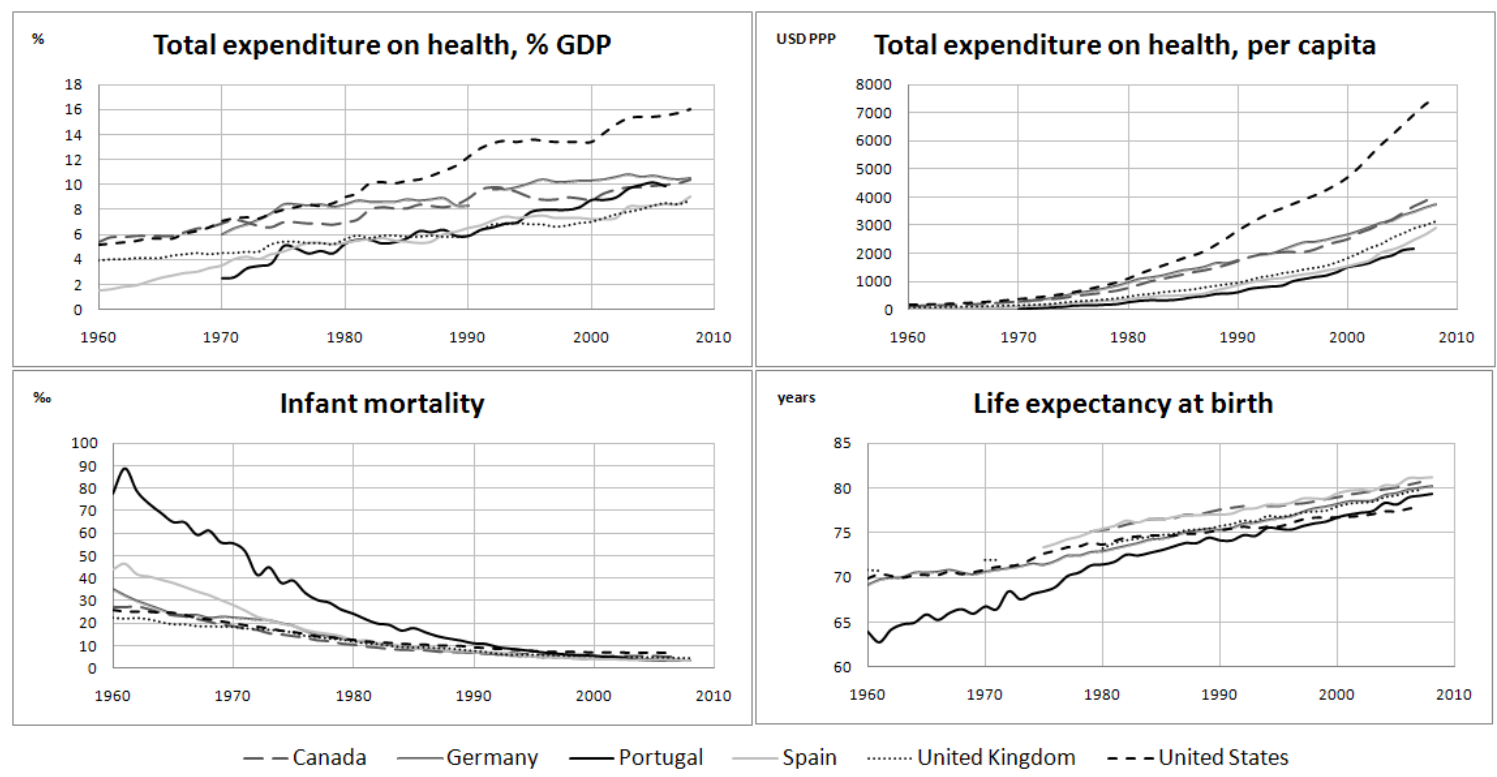

Figure 1 Healthcare evolution, 1960-2008 (source: [2])

In this context, hospital managers and other authorities have naturally been giving more importance to enhancing healthcare supply chains through cooperative purchasing strategies.

From a supply chain perspective, the improvement of purchasing strategies typically implies intensifying integration and increasing purchasing centralisation, supported by information and communication technologies for real-time information sharing, and promoting order consolidation to reduce unit costs [5]. Thus, spontaneous horizontal

\footnotetext{
${ }^{1}$ Source: Hospital Systems Profit and Loss Accounts
} 
cooperation between neighbour hospitals, with the objective of controlling purchasing costs and sharing supply chain management knowledge, should be encouraged. However, purchasing groups often experience difficulties in their implementation, thus justifying additional support to maximise their chances of success [6].

In this work, we propose a flexible approach to recommend and evaluate a Group Purchasing Organisation (GPO) structure (i.e., the number of GPOs to form, their size and composition) for a set of hospitals willing to cooperate, while minimising their shared supply chain costs. Our approach combines the recommendation of a GPO structure with the use of an optimisation procedure to determine the supply chain configuration of the resulting GPOs (i.e., where, when and in which quantities supplied items are stored and flow in the supply chain). This integration enables the identification of synergies within each possible GPO.

The problem is solved by a two-module optimisation approach that incorporates a hybrid VNS / Tabu Search metaheuristc, and that can be adapted to the analysis of cooperative purchasing strategies in hospital supply chains involving the establishment of various types of GPOs.

Our approach can be easily used to support a group of hospitals intending to form a GPO, since the decision makers (the managers of the hospitals involved in a collaboration process) only need to provide information about the structure of their supply chains (suppliers, distribution centres, storage locations, places where demand occurs, and the possible supply links between these points) and some transactional data (e.g., the demand of items at relevant places, prices and discount schemes of alternative suppliers, fixed administrative costs of establishing commercial relations with these suppliers, an interest rate for inventory holding cost calculation, existing storage 
capacity constraints). In return, they get detailed reports comparing the costs of various cooperation alternatives.

Moreover, the approach is flexible enough to be applied to simplified versions of the problem, for example, by aggregating demand at upstream points in the supply chain, and by considering only some of the costs.

Schotanus [7] points out that no instruments have yet been developed to determine the optimal size of purchasing groups under different circumstances (e.g., different markets, price elasticity, etc.), Schoenherr et al. [8] highlight the need for research that improves the understanding of mechanisms for the design and control of processes which enable joint value creation and sharing (namely, sharing of cost savings resulting from joint cost reduction efforts), and Walker et al. [9] state that developing tools for calculating the benefits of cooperative purchasing is an enabler of collaboration. The proposed approach links GPO formation with the optimisation of the resulting joint supply chain. This integration points out the supply chain design directions for the specific cooperative situation being evaluated. Additionally, it facilitates the analysis and negotiation processes for cooperative purchasing initiatives, by exposing financial impacts for the group and for individual hospitals, thus enhancing communication and fostering negotiations on the allocation of cooperation costs and gains.

This paper is structured as follows. First, we relate our problematic situation to cooperative purchasing, namely in a healthcare setting and taking a supply chain perspective, and we frame that situation by describing the evolution of healthcare GPOs in Portugal. Second, we explain and formulate a model for the problem. We then solve our model using a two-module optimisation method and we present an illustrative example to show the benefits of the approach. Finally, we draw some conclusions and propose lines for further research. 


\section{Literature review}

\subsection{Cooperative purchasing}

Cooperative purchasing (also referred to as group purchasing, collaborative purchasing, collective purchasing, joint purchasing, consortium purchasing, shared purchasing, bundled purchasing, pooled purchasing, alliance purchasing, etc.) is the horizontal cooperation between two or more organisations in one or more steps of the purchasing process, by pooling and/or sharing their purchasing volumes, information, market and demand risks and/or resources $[10,11,4]$. The resulting initiatives have originated a wide diversity of cooperative organisations that range from informal/virtual arrangements to third party (formal) outsourcing, broadly designated as purchasing groups or group purchasing organisations (GPOs) (see a summary of possible typologies in [11]).

In Table 1 we summarise the most frequently stated advantages and disadvantages of GPOs, as well as some areas where there are doubts about their benefits. Many of the existing research findings depend on the purchasing group type under analysis, and therefore it is important to clearly classify and define those types in order to identify which advantages, disadvantages, critical success factors, drivers and preconditions apply to which group type(s) [7]. Purchasing groups are much more frequent in the public sector [12] and an important part of the existing research on cooperative purchasing focuses on healthcare GPOs. In general, results from other sectors may be transposed to healthcare, but the special characteristics of this industry may require some specific analysis. Accordingly, in Section 2.3 we briefly discuss this topic further, focusing in a healthcare context. 
Table 1 Group purchasing advantages and disadvantages

\section{At individual member level}

\section{Advantages}

- reduction of purchasing related costs (namely, acquisition costs (e.g., [4,12,15-17]), transaction costs (e.g., [4,16-18]), administrative costs (e.g., [12,17,19,20])

- human resources savings, since some purchasing effort is transferred to the group [21,17]

- increased information on supply markets [18]

- increased focus on core operational activities (e.g., [17,21])

\section{Disadvantages}

- standardisation decreases the ability to fulfil the needs of decentralised users (e.g., [5])

- lower innovation capabilities (at contract [22] and product/ service levels [23]), due to compromise [22], standardisation, and reduction of direct contacts with suppliers [23]

- lower responsiveness [5], e.g., in case of a small scale emergency situation [23]

\section{Doubts/ Concerns}

- prices negotiated by purchasing groups may be higher than those negotiated directly with vendors [14]

\section{At group/ supply chain level}

\section{Advantages}

- consolidation of purchase volumes enables the negotiation of more favourable terms with suppliers $[5,17,18,23]$

- reduction of duplicated purchasing efforts (e.g., [5]), namely, through reduction of the number of transactions (e.g., [12,18])

- development of purchasing expertise [5]

- rationalised choice through better-informed selection and standardisation (e.g., [19,23])

- standardisation and consolidation of purchasing volumes increase economies of scale (e.g., at supplier level), lowering unit costs for the whole supply chain $[23,16]$

- improved ability to respond to large scale emergency situations [23], due to increased flexibility of inventories [18], coordination [23] and resource pooling [23]

Disadvantages
• coordination costs (e.g., [16,23]), mainly when GPO size increases [7]

At macro/ political level

\section{Advantages}

- reduction of overall supply chain costs, that, in the public sector, implies that the amount paid by tax payers decreases [19]

- in the public sector, prevention/ reduction of corruption $[12,13]$

\section{Disadvantages}

- consolidation of sales volumes may inhibit SMEs from participating in the tenders $[23,9]$

- may be a barrier to innovation, because GPOs tend to favour suppliers with broad product lines rather than a single innovative product [24]

\section{Doubts/ Concerns}

- risk of a negative effect in market dynamics due to excessive buyer concentration [25]

- risk of a negative effect in market dynamics due to the introduction of an additional intermediary, in case of third party GPOs (e.g., [26])

- depending on the market at stake, an increase in the concentration of the buyers (demand side) may counterbalance the excess concentration on the supply side, improving competition conditions [25] 
The size of the purchasing group may have a significant impact on its financial performance since the involvement of many members may lead to higher set-up and transaction costs but, on the other hand, the involvement of few members may lead to smaller economies of scale. Nevertheless, research has indicated that in healthcare purchasing there is no direct relationship between higher volumes and lower prices [e.g., 13,14].

Schotanus [7] points out that no instruments have yet been developed to determine the optimal size of purchasing groups under different circumstances (e.g., different markets, price elasticity, etc.). However, it should be noted that the optimal purchasing group size strongly depends on the type of purchasing group under consideration (see, e.g., $[10,11])$

\subsection{Cooperative purchasing in supply chains}

Although cooperative purchasing initiatives have been widely applied, there is very few research concerning the integrated analysis of purchasing groups formation with the coordination of the supply chains of the cooperating organisations. Our approach links the evaluation of the potential purchasing groups with an optimisation procedure, in order to determine their common supply chain configuration. This integration takes into consideration not only the most recognised benefits of cooperation, such as obtaining quantity discounts or transaction and administrative costs savings, but also other possible supply chain synergies, achieved, for example, through inventory pooling, inventory lateral transhipments, or distribution consolidation. Moreover, it supports the operationalization of existing supply chains to the new cooperative situation. 
From a supply chain point of view, our approach can be viewed as being related to the broad supply chain coordination literature (see [27,28]) and to the literature on cooperative ordering / lot sizing models (see [29,30]).

The main distinctive features of our approach in comparison with previous works are the following:

- The determination of the best GPO structure (Section 3.2) for a group of cooperating organisations (in our case, hospitals) integrated with the multi-period optimisation of the resulting GPO supply chains, computing the costs of all participants and combining (for the first time, as far as we are aware of) the following characteristics: interrelated purchasing, distribution and inventory decisions; more than two echelons; multiple suppliers; multiple products; quantity discounts; fixed costs; pathdependent costs; and bundled storage and supply capacity constraints.

- Its flexibility, since it can be used to optimise problems with different supply chain configurations (e.g., number of echelons, suppliers, hospitals, hospital wards and/or products) as well as different cost types.

\subsection{Cooperative purchasing in healthcare}

Given the increasing need to rationalise healthcare services, there have been diverse attempts to improve the efficiency and effectiveness of hospital systems through vertical or horizontal, and direct or indirect supply chain collaboration. Besides cooperative purchasing, these efforts have included the stockless system (described in [31]), Vendor Managed Inventory (VMI) systems (e.g., [32]), resource sharing/pooling by neighbour healthcare providers (e.g., [33,34]), e-commerce (e.g., [35]) and/or e-communication, namely, in the area of telemedicine (e.g., [36]), integrated care [37], and other integration initiatives (see [38]). 
The full success of many of these experiences has been hindered by difficulties in communication, leadership or conflicting interests conciliation (e.g., [32,39-42]), or by suspicions about the fair distribution of costs and benefits of the collaboration processes (e.g., $[33,41])$. Communication problems $[22,6]$ and the allocation of savings [7] are two of the main difficulties of purchasing groups for informally structured programme groups [10], i.e., groups having the characteristics of the group of our research case (Section 3.1).

In healthcare these difficulties may be larger as the supply chain is managed through a complex line of command, based on a sensitive balance of power relationships among diverse highly trained professional groups (managers, physicians, nurses, pharmacists, etc.) that work at autonomous units [43]. The system is also highly dependent on the role played by physicians [44], as they develop long run relationships with suppliers and preferences on specific materials and products, reflecting, for example, their education in specific medical schools.

The knowledge about the supply chain, and the awareness of the impacts of certain decisions on its operation, may improve the willingness to discuss alternative actions to develop collaboration between supply chain members (e.g., [45]). Moreover, as stressed by Ford et al. [41], understanding which individuals stand to lose or gain within a particular collaborative initiative can yield critical insights into the prospects for the success of a project.

Burns and Lee [4] conducted an independent survey of materials managers for hospitals in the US, concerning their national purchasing alliance usage, and confirmed the conclusions of Schneller [21] that GPOs help contain rising healthcare costs by reducing product prices in two ways: (1) through pooled purchasing leverage of hospitals buying products on nationwide contracts; and (2) through the establishment of price ceilings 
beneath which hospitals negotiate on their own. They also concluded that alliances may also benefit hospitals financially by reducing transaction costs.

In summary, previous research has confirmed that cooperative purchasing can significantly reduce costs related to hospital systems purchasing activities. However, it is also clear how important it is to incorporate a supply chain perspective into GPO analysis and to prepare potential cooperation processes, by analysing and negotiating possible forms of cooperation and their consequences to the group and also to individual participants, so that adequate incentive alignment and goal congruence can be reached. Since GPO size and characteristics may influence the extent and nature of achieved benefits, models to analyse GPO formation should take these aspects into account.

\section{Problem}

\subsection{Research case}

Our research was motivated by the observation of a group of neighbour public hospital systems that are physically close, and that have established some purchasing cooperation relations and launched several joint tenders. This group was formed by a core set of four neighbour hospital systems (totalizing 10 hospitals), responsible for more than $20 \%$ of the total pharmaceuticals consumption by public hospitals in Portugal [3], but with time has involved the participation of other systems. One of the cooperating hospitals is widely recognised as a centre of knowledge and innovation, and its initiatives are easily followed by other hospitals (belonging or not to the purchasing group), and consequently, the possibility of not doing business with this hospital can be very negative to a supplier, especially when a prestigious brand is at stake. Thus, in 
some situations, this hospital can take the leading role in the negotiation of on-contract prices with suppliers. Representatives of the management teams of these hospitals meet weekly to discuss cooperative projects (e.g., the definition of a common master file of medical-surgical products, the standardisation of pharmaceuticals use, and the organisation of purchasing processes) or to share their experiences and opinions about supply chain best practices. The participating hospital systems do already share information as required by our approach (namely, demand and prices obtained from suppliers). Since all group members have strong relationships with each other and all can influence specifications, this purchasing group can be considered as an informally structured programme group [10].

It may be argued that the best solution for Portuguese public hospitals would be the establishment of a national GPO. In fact, over the years, we have seen repeated attempts from national health authorities to implement and manage national purchasing groups. However, the proportion of purchases channelled through these organisations has been quite small and they have recurrently experienced limited acceptance or even resistance from hospitals, especially when involving mandatory compliance rules. The introduction of healthcare GPOs in Portugal has in fact followed a path opposed to the commonly observed evolution phases of group purchasing development, as described by D'Aunno \& Zuckerman [46], Johnson [16], Nollet \& Beaulieu [47] or Schotanus et al. [6], and probably this is one of the reasons why the results achieved by these first attempts have been so disappointing. Other reasons may be the heterogeneity of Portuguese hospital systems in terms of dimension (and consequently, demand volume), financial situation (and consequently, payment period) and accessibility. Since suppliers had to present their price offers based on a forecast of potential annual sales, without knowing the locations of their client hospitals, or the payment dates, the prices offered 
to GPOs were often considerably higher than those obtained by individual hospital systems through direct negotiations.

These failed experiences further reflect the gap between policy goals and the realities of the hospital systems involved in these purchasing groups, as identified by Schotanus et al. [6]. Moreover, these authors concluded that "no enforced participation" is the most important success factor for managing a purchasing group, since the cost-effectiveness of a well-organised group should attract members without forcing them to formally cooperate [6].

The four hospital systems observed in this study meet many of the favourable conditions for increased purchasing centralisation [48,6]: they are not direct competitors, since NHS hospitals access does not depend on patient choice, all members have a similar influence in the group and similar objectives, they are geographically near to each other, they have common consumption of items and purchasing requirements, their supply markets are often highly concentrated, the savings potential of purchasing cooperation is high, and their purchasing processes require high expertise. At the current stage, the proposed solution for this set of hospitals is the consolidation of purchasing cooperation, without mandatory compliance, but they need to determine which are the best cooperation arrangements, to anticipate the global and individual savings they will achieve, and to find out how to organise their joint supply chain in order to take the maximum advantage from cooperation. The actual needs of this group of hospitals, as observed in practice, were the real motivation for the approach described in this work. 


\subsection{Model description}

In this work we consider a cooperative game, defined on the real situation of a group of neighbour hospitals engaged in an information sharing process with the objective of purchasing items cooperatively. The motivation of these hospitals was to significantly decrease costs, while meeting quality and usability requirements. In past cooperation initiatives, they had already established some binding and benefits sharing agreements. In spite of these experiences and the intent to deepen cooperation, it was quite clear that the identification and sharing of cooperation costs and benefits was not a simple task.

The theory of cooperative games is concerned with situations in which players (in our case, hospitals) can negotiate effectively. I.e., if there is a feasible change in the strategies of the coalition members that might benefit all of them, then they would agree to actually make such a change, unless it contradicts agreements of some members of the coalition with other outside players [49]. For this purpose, any of the $2^{\mathrm{N}}-1$ nonempty subsets of the total set of $\mathrm{N}$ players under consideration is a potential coalition.

The adoption of a cooperative game perspective makes sense in situations where the players have incentives to improve their game payoffs, by adding communication or (explicit or implicit) contract-signing options, providing some control over the actions of other players, with the objective of transforming the initial game into a game with equilibria that are better for all the players [49].

Cooperative games are based on three necessary conditions [41,50]: (1) every actor's motivation is known by the others; (2) legally binding agreements exist between the coalition members; and (3) all benefits derived from cooperation are returned to the members in a way they consider equitable. In case one of the previous conditions is absent, even if hospitals have the intention to cooperate, we have a non-cooperative 
game and, for the GPO to survive, each player should receive at least as much from participating in the group as he would receive by operating unilaterally.

In a cooperative game with more than two players, the possibility of cooperation among subsets of the players should be considered, and the resulting potential structure of the sequential negotiations between the participants of all possible coalitions is, in real situations, very complex [49].

As the problem under analysis represents a situation where an important part of the cooperation benefits can be measured by financial outcomes that can be transferred between purchasing group members, we can apply the commonly used transferable utility assumption.

For the purposes of this work, a GPO (coalition) is any nonempty subset of the set of hospitals (players) involved in the cooperative game (i.e., those with the intention to cooperate with each other), and a GPO structure is a partition of the hospitals (players) into disjoint, exhaustive GPOs (coalitions). Therefore each hospital belongs exactly to one GPO, and some GPOs may be composed of one single hospital.

Our approach compares all possible GPOs (coalitions) formed from a group of $\mathrm{N}$ hospitals (players), and recommends the GPO structure that minimizes the total cost for the global solution. It also provides information about alternative GPO structures and about the individual hospital participation in the final solution, thus supporting a possible negotiation phase to (re)allocate cooperation results.

The number of possible GPO structures equals $\sum_{i=1}^{N} Z(N, i)$, where $Z(N, i)$, known as the Stirling number of the second kind, is the number of GPO structures with $i$ GPOs formed from $N$ hospitals willing to cooperate. The easiest approach to enumerate Stirling numbers is recursion, with $Z(N, i)=Z(N-1, i-1)+i Z(N-1, i)$, and $Z(N, N)=Z(N, 1)=1$. Figure 2 illustrates the case of a group of 5 individual 
hospitals, showing how the $31\left(2^{5}-1\right)$ potential GPOs can be associated to form GPO structures.

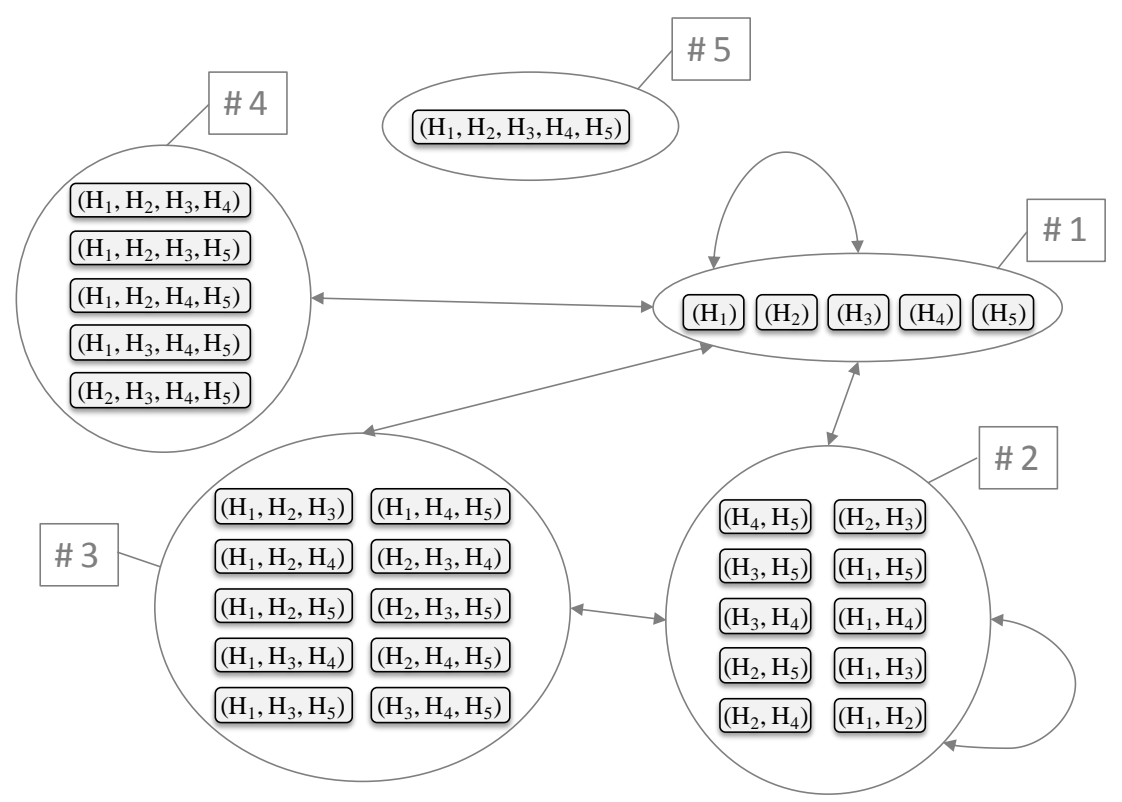

Figure 2 Potential GPOs originated from a group of 5 hospitals and how they form GPO structures

Figure 3 lists the 52 possible GPO structures composed from those 31 potential GPOs. Nodes represent all possible GPO (coalition) structures. At the top of the figure, we have a coalition composed by all the five hospitals, and at the bottom, we have the five hospitals purchasing individually. Arcs represent mergers of two coalitions when going upwards, and splits of a coalition into two when going downwards [51]. It is easy to see that the number of GPO structures grows exponentially with the number of hospitals (e.g., if we had 9 hospitals, we would have 21147 GPO structures).

Our approach consists of a recursive two-module method, where module 2 is a procedure performed inside module 1, as described in Figure 4. 


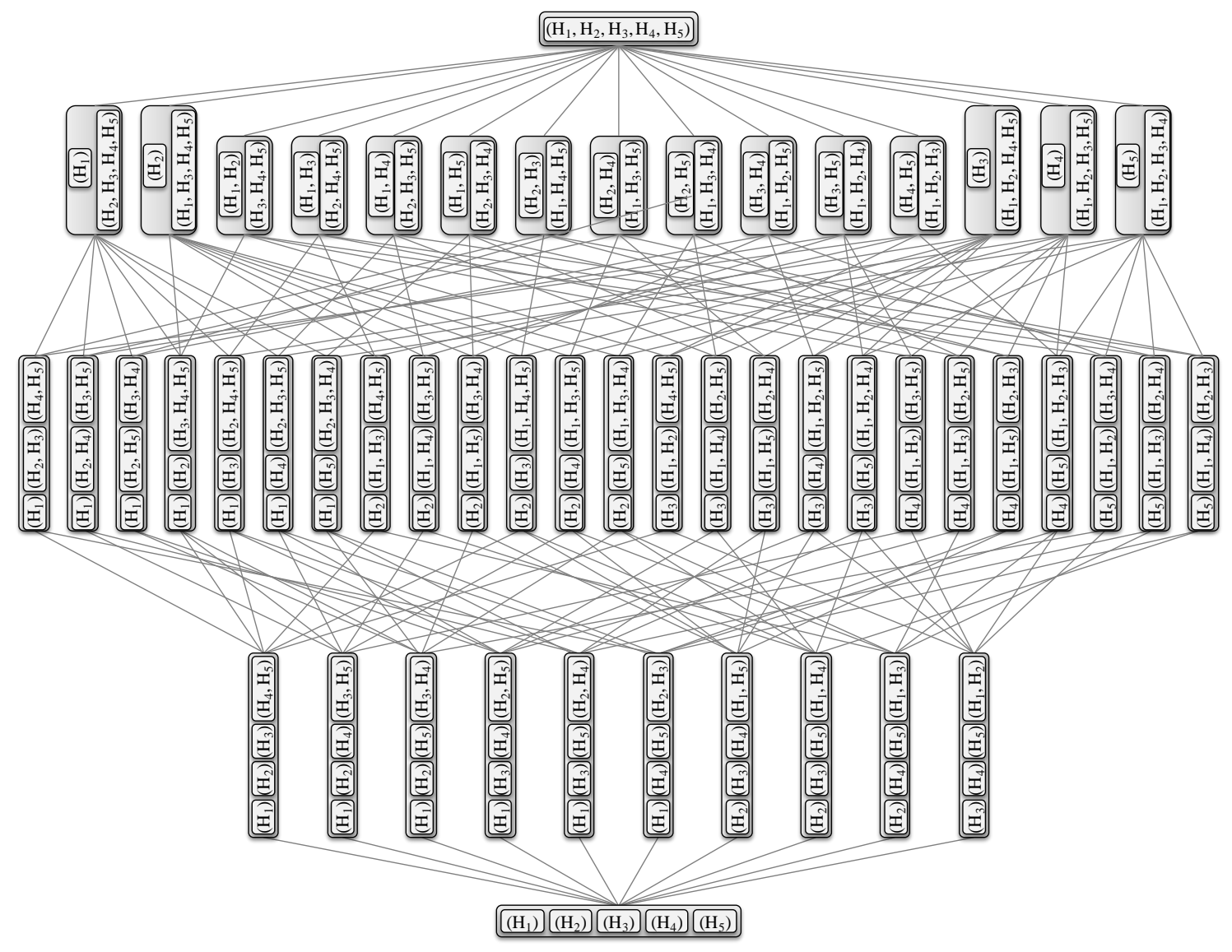

Figure 3 GPO structure graph for a 5-hospital game (adapted from [51])

Module 2 is intended to optimise each potential GPO supply chain, by using a modified version of a model developed in a previous work [52]. This model was inspired by the formulation from Ahuja et al. [53] considering a multi-stage, multi-level, multi-product production-distribution system planning problem, based on a graph representation of the problem. The multi-period dimension of the problem is taken into account in the model through the replication of the supply chain with "inventory edges" connecting storage areas (at hospital distribution centres and point of care units) in subsequent periods. A version of this problem considering one network entity at each supply chain echelon (as described in Section 3.3) is NP-hard, if the model includes fixed supply costs that are independent from supplied quantities [53]. Since our model considers this type of costs, while admitting more than one network entity at each supply chain echelon, it is also NP-hard. Furthermore, the objective function of the problem is non-linear and non- 
convex (e.g., the number of edges in a solution varies), thus increasing the complexity of the problem.

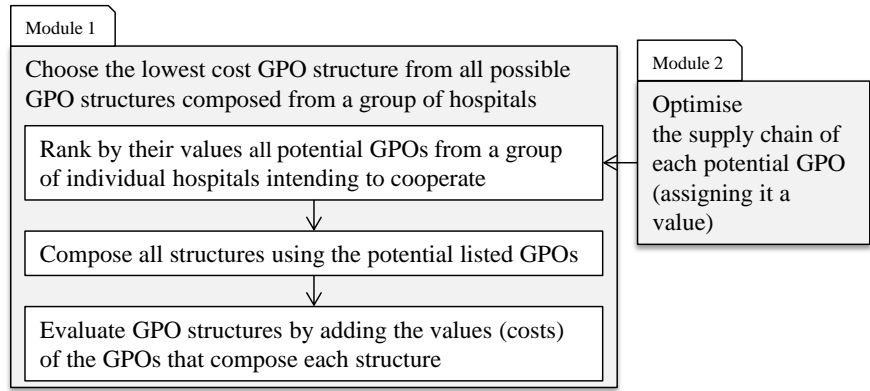

Figure 4 Optimisation approach

Figure 5 illustrates the application of this modelling logic to a very simple supply chain: two producers $\left(\mathrm{P}_{1}\right.$ and $\left.\mathrm{P}_{2}\right)$, an informal GPO (i.e., a virtual organisation that centralises GPO purchases) and two cooperating hospitals with five point of care units each $\left(\mathrm{U}_{11}\right.$, $\mathrm{U}_{12}, \ldots \mathrm{U}_{15}$, and $\mathrm{U}_{21}, \mathrm{U}_{22}, \ldots \mathrm{U}_{25}$ ), during five purchasing periods. A point of care unit is a location where final demand occurs (i.e., where it is traced). These locations may have a space for inventory storage. In practice, they may be wards or parts of wards. Solving this model means determining a relatively low cost way of fulfilling the demand of all the point of care units, by identifying all necessary network supply paths, i.e., sequences of consecutive supply and/or storage edges linking a producer to a point of care unit, and valued by the item quantity that is supplied through them.

A supply edge links one network entity to another in one time period (e.g., producer 1 in period 1 to hospital 1 in the same period), and represents physical (or virtual, if a GPO is involved) supplies of items between those two entities. The flexibility of the model allows the decision maker to consider the alternative of supplying the point of care units directly from the producer (as in a VMI scheme), as represented by the direct arcs from the producer to the point of care units in period 1 . This possibility is not graphically represented in the following periods to preserve the readability of the figure. 
A storage edge is represented by a dashed edge linking one network entity in one period to the same entity in the following period (e.g., hospital 1 in period 1 to hospital 1 in period 2) and represents the possibility of storing inventory at that location from one period to the next.
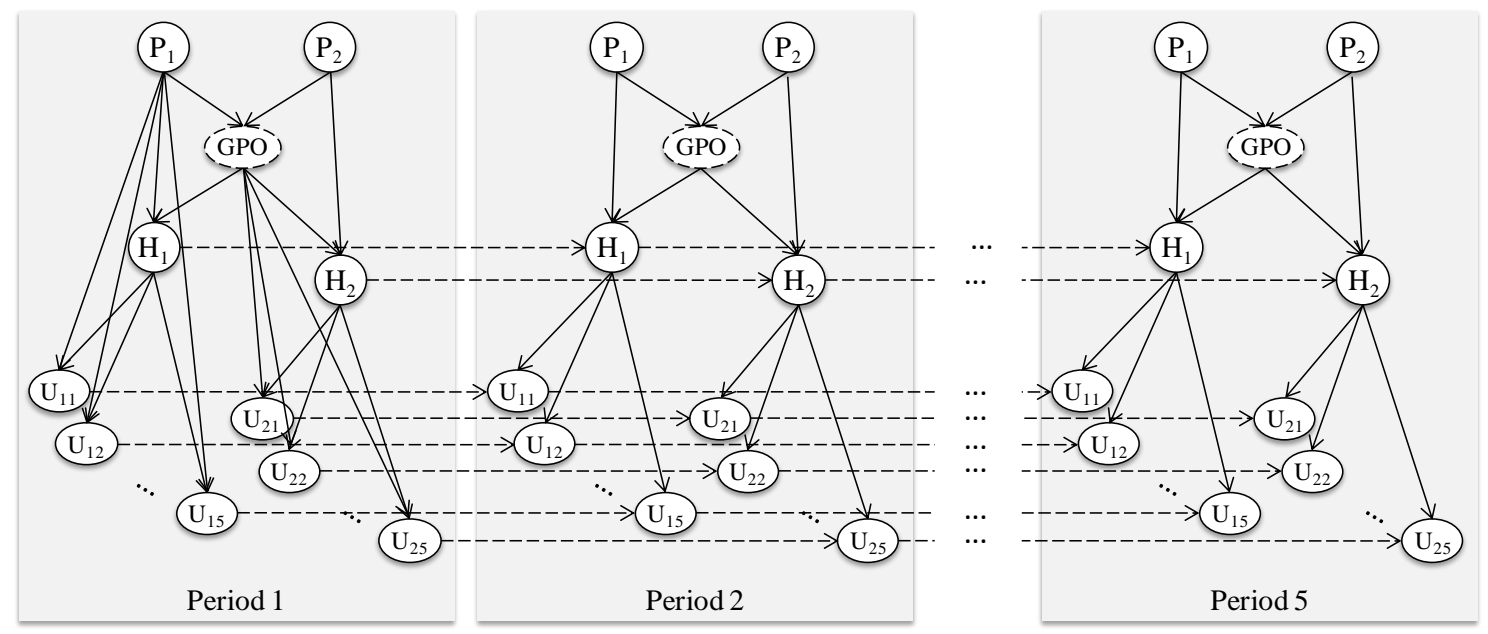

Figure 5 Illustration of the model (adapted from [52])

The model considers: (1) fixed administrative costs for establishing commercial relationships between a supplier and a customer, e.g., costs of negotiation and contracts; (2) fixed and (3) variable transaction costs; (4) acquisition costs, including GPO margins (or discounts); and (5) inventory carrying costs [52]. In line with what has been observed in practice, we added an acquisition cost scheme considering bundle supplier discounts depending on the aggregate sales of the GPO (or individual hospital) during the planning horizon under consideration.

Due to the nature of the acquisition and inventory carrying costs considered, our mathematical formulation cannot be based on the structure that is frequently found in the literature (some examples can be found in [54]), that associates the decision variables to the quantities that flow through the network edges. Therefore, as any item flowing through a specific edge can have different costs, depending on its previous path 
(see a few examples in [52]), our formulation associates the supplied quantities to the network supply paths (several edges) that have been used.

In what follows we assume that all relevant data (costs, capacities, and other parameters) have been collected using appropriate estimation/forecasting methods and a hospital-specific business analysis.

\subsection{Model formulation}

\section{Sets and indices}

$G=\{1,2, \ldots g, \ldots\}-$ items

$C=\{\ldots, \gamma, \ldots\}-$ potential GPOs (coalitions); $\#(C)=2^{\mathrm{N}}-1$, where $\mathrm{N}$ is the number of potentially cooperating hospitals (e.g., in a 5 hospitals problem there are 31 potential GPOs)

$R_{\gamma}=\{1,2, \ldots, i, j, \ldots\}-$ network entities (suppliers, hospitals, intermediaries, and point of care units) in a potential GPO $\gamma$

$K_{\gamma}=\{1,2, \ldots k, \ldots\}-$ network supply paths for potential GPO $\gamma$

$H_{\gamma}=\{1,2, \ldots h, \ldots\}-$ hospitals; $H_{\gamma}$ is a subset of $R_{\gamma}$

$E_{\gamma}=\{1,2, \ldots e, \ldots\}-$ demand entities (point of care units); $E_{\gamma}$ is a subset of $R_{\gamma}$

$E_{\gamma}^{h}$-demand entities that are part of hospital $h ; E_{\gamma}^{h}$ are subsets of $E_{\gamma}$

$L=\{1,2, \ldots l, \ldots\}-$ suppliers; $L$ is a subset of $R_{\gamma}$

$\theta_{\gamma}=$ organisation (maybe virtual or informal) that centralises potential GPO $\gamma$ purchases; $\theta_{\gamma}$ is a subset of $R_{\gamma}$

$S=\left\{1,2, \ldots, p, t, \ldots s_{\max }\right\}-$ periods of the planning horizon

$\mathrm{CS}=\{\ldots \chi, \ldots\}-$ GPO (coalition) structures (e.g., in a 5 hospitals problem we have 52 potential GPO structures)

Figure 6 illustrates the way each node or edge is identified. An edge can be classified as a "supply edge", if it links different entities in the same period, i.e., when $(i \neq j) \wedge(p=t)$, or as a "storage edge" if it links one entity in different, consecutive periods, i.e., when $(i=j) \wedge(t=p+1)$. 


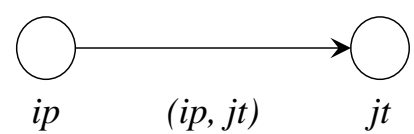

Figure 6 Edge (ip, jt) links entity $i$ in period $p$ to entity $j$ in period $t$

\section{Costs}

$a_{i j}=$ fixed administrative cost of establishing a commercial relationship between entity $i$ and entity $j$

$f_{i j}=$ fixed transaction cost from entity $i$ to entity $j$

$v_{g i j}=$ cost of transacting one unit of item $g$ from entity $i$ to entity $j$

$b_{g i p}=$ rate (applied to the aggregated acquisition cost) used to calculate the cost of maintaining one unit of item $g$ stored at entity $i$ from period $p$ until period $p+1$

$w_{g l j}=$ price at which supplier $l$ sells each unit of item $g$ to entity $j$

$m_{g i j}=$ commercial margin that intermediary $j$ adds to the acquisition cost of item $g$ when he/she buys one unit of it from supplier $i$

\section{Other parameters}

$d_{g i t}=$ demand of item $g$ by entity $j$ in period $t$

$S C_{i}=$ storage capacity of entity $i$

$F C_{g i p}=$ supply capacity of item $g$ by entity $i$ in period $p$

\section{Decision variables}

$Q_{g k}=$ quantity of item $g$ that flows through path $k$

$X_{i p j t k}=\left\{\begin{array}{l}1, \text { if edge (ip, } \mathrm{jt}) \text { belongs to path } \mathrm{k}, \text { with }(\mathrm{j} \geq \mathrm{i}) \wedge(\mathrm{t} \geq \mathrm{p}) \\ 0, \text { otherwise }\end{array}\right.$

$\chi=\mathrm{GPO}$ structure

$\phi_{\gamma \chi}=\left\{\begin{array}{l}1, \text { if GPO } \gamma \text { belongs to GPO structure } \chi \\ 0, \text { otherwise }\end{array}\right.$

\section{Intermediate variables}

$Y_{i p j t}=\left\{\begin{array}{l}1, \text { if }(\mathrm{ip}, \mathrm{jt}) \text { is a supply edge, i.e., if }(\mathrm{p}=\mathrm{t}) \wedge(\mathrm{i} \neq \mathrm{j}) \\ 0, \text { otherwise }\end{array}\right.$ 
$Z_{i p j t}=\left\{\begin{array}{l}1, \text { if }(i p, j t) \text { is a storage edge, i.e., if }(\mathrm{t}=\mathrm{p}+1) \wedge(\mathrm{i}=\mathrm{j}) \\ 0, \text { otherwise }\end{array}\right.$

It must be noted that supply edges are never storage edges and the opposite is also true.

Additionally, all edges in the model should be either supply or storage edges.

$A_{i j}=\left\{\begin{array}{l}1, \text { if the supply link between } \mathrm{i} \text { and } \mathrm{j} \text { is used, i.e., if } \sum_{g} \sum_{p} \sum_{t} \mathrm{X}_{\mathrm{ipjtk}} \mathrm{Y}_{\mathrm{ipjt}} Q_{g k} \geq 1, \forall(i, j) \text { with } i, j \in R_{\gamma} \\ 0, \text { otherwise }\end{array}\right.$

$e_{g k r s}=$ acquisition cost of one unit of item $g$ at the entry of node $r s$ (i.e., at the entry of entity $r$ at the beginning of period $s$ ) belonging to path $k$

$q_{g l j}=$ aggregated quantity of item $g$ bought by entity $j$ to supplier $l$

$o_{g k r s}=$ aggregated inventory carrying cost of one unit of $g$ at the entry of node $r s$ (i.e., at the entry of entity $r$ at the beginning of period $s$ ) belonging to path $k$

Total fixed administrative cost $=\sum_{i} \sum_{j} A_{i j} a_{i j}$

Total fixed transaction cost $=\sum_{k} \sum_{i} \sum_{p} \sum_{j} \sum_{t} X_{i p j t k} Y_{i p j t} f_{i j}$

Total variable transaction cost $=\sum_{k} \sum_{i} \sum_{p} \sum_{j} \sum_{t} X_{i p j t k} Y_{i p j t} Q_{g k} v_{g i j}$

Total acquisition cost $=\sum_{g} \sum_{k} \sum_{i} \sum_{p} e_{g k i p} Q_{g k}$

with:

$$
e_{g k r s}=\left\{\begin{array}{l}
e_{g k i p}, \text { if } Z_{i p r s}=1, \\
\sum_{i} \sum_{p} \sum_{j}^{j<r} \sum_{t}^{t \leq s}\left(w_{g l j} X_{i p j t k} Y_{i p j t}\right) \times \prod_{i} \prod_{p} \prod_{j}^{j<r} \prod_{t}^{t \leq s}\left[1+\left(m_{g i j} X_{i p j t k} Y_{i p j t}\right)\right], \\
\text { if } Y_{i p r s}=1, \quad \forall g \in G, \forall k \in K_{\gamma}, \forall r \in R_{\gamma}, \forall s \in S
\end{array}\right.
$$


where,

$$
w_{g l j}=\left\{\begin{array}{cc}
w_{g l j}^{0}, & \text { if } 0 \leq q_{g l k}<\delta_{1} \\
w_{g l j}^{1}, & \text { if } \delta_{1} \leq q_{g l k}<\delta_{2} \\
\ldots & \ldots \\
w_{g l j}^{n}, & \text { if } \delta_{n} \leq q_{g l k}<+\infty
\end{array}\right.
$$

with:

$q_{g l j}=\left\{\begin{array}{c}\sum_{k} \sum_{i} \sum_{p} \sum_{j \in \theta_{\gamma}} \sum_{t} X_{i p j t k} Y_{i p j t} Q_{g k}, \quad \forall i \in L, \forall g \in G, \quad \text { if } j \in \theta_{\gamma} \\ \sum_{k} \sum_{i} \sum_{p} \sum_{j \in H_{\gamma}} \sum_{t} X_{i p j t k} Y_{i p j t} Q_{g k}+\sum_{k} \sum_{i} \sum_{p} \sum_{j \in E_{h}} \sum_{t} X_{i p j t k} Y_{i p j t} Q_{g k}, \\ \forall g \in G, \forall i \in L, \quad \text { if }\left(j \in H_{\gamma}\right) \vee\left(j \in E_{\gamma}^{h}\right)\end{array}\right.$

The above expressions allow us to model the following requirements. When passing through a storage edge (5), the acquisition cost of one unit of item $g$ is maintained but, when passing through a supply edge (6), this cost is adjusted considering the price at which entity $i$ sells item $g$, or the commercial margin that intermediary $j$ adds to the cost at which he acquires one unit of that item. The value of the demand used to determine the price at which supplier $l$ sells each unit of item $g$ to entity $j$ (7) is computed by aggregating all the demand channelled through the informal organisation that centralises each potential GPO purchases or all the demand channelled through the individual hospitals (including their point of care units) during the planning horizon considered. The model does not assume enforced GPO participation, i.e., hospitals can buy directly from suppliers. 
Total inventory carrying cost $=\sum_{g} \sum_{k} \sum_{i} \sum_{p} o_{g k i p} Q_{g k}$, with:

$$
o_{g k r s}=\left\{\begin{array}{l}
o_{g k i p}, \text { if } Y_{i p r s}=1, \\
o_{g k i p}+\left(e_{g k r s}+o_{g k i p}\right) b_{g r s} X_{i p r s k} Z_{i p r s}, \text { if } Z_{i p r s}=1, \\
\quad \forall g \in G, \forall k \in K_{\gamma}, \forall r \in R_{\gamma}, \forall s \in S, \text { with } i \in R_{\gamma}, p \in S
\end{array}\right.
$$

The unit inventory carrying cost (9) is maintained when passing through a supply edge, and it is adjusted when passing through a storage edge. This adjustment is done by using a rate (applied to the aggregated acquisition cost) that considers the cost of maintaining one unit of item $g$ stored at entity $i$ from period $p$ until period $p+1$.

\section{Model}

Module 1:

Minimise $\quad V(\chi)=\sum_{\gamma \in \chi} V(\gamma) \varphi_{\gamma \chi}$

Module 2:

$$
\begin{aligned}
V(\gamma)=\operatorname{Min}\left(\sum_{i} \sum_{j} A_{i j} a_{i j}+\sum_{k} \sum_{i} \sum_{p} \sum_{j} \sum_{t} X_{i p j t k} Y_{i p j t} f_{i j}+\right. \\
+\sum_{k} \sum_{i} \sum_{p} \sum_{j} \sum_{t} X_{i p j t k} Y_{i p j t} Q_{g k} v_{g i j}+ \\
\left.\quad \sum_{g} \sum_{k} \sum_{i} \sum_{p} e_{g k i p} Q_{g k}+\sum_{g} \sum_{k} \sum_{i} \sum_{p} o_{g k i p} Q_{g k}\right)
\end{aligned}
$$

Subject to:

$$
\begin{aligned}
& \sum_{j} \sum_{t} X_{00 j t k}=1, \quad \forall k \in K_{\gamma} \\
& \sum_{i} \sum_{p} X_{i p r s k}=1, \quad \forall k \in K_{\gamma}, \forall r \in R_{\gamma}, \forall s \in S
\end{aligned}
$$




$$
\begin{aligned}
& \sum_{j} \sum_{t} X_{r s j t k}=1, \quad \forall k \in K_{\gamma}, \forall r \in R_{\gamma}, \forall s \in S \\
& \sum_{k} \sum_{i} \sum_{p}^{s_{\text {max }}} Q_{g k} \cdot X_{i p r s k} Y_{i p r s}+\sum_{k} \sum_{i} \sum_{p}^{s_{\max }} Q_{g k} \cdot X_{i p r s k} Z_{i p r s}-\sum_{k} \sum_{j} \sum_{t}^{s_{\max }} Q_{g k} \cdot X_{r s j t k} Y_{r s j t}- \\
& -\sum_{k} \sum_{j} \sum_{t}^{s_{\text {max }}} Q_{g k} \cdot X_{r s j t k} Z_{r s j t}=d_{g r s}, \quad \forall g \in G, \forall r \in R_{\gamma}, \forall s \in S \\
& \sum_{k} \sum_{j} \sum_{p} Q_{g k} \cdot X_{i p j t k} Y_{i p j t} \leq F C_{g i p}, \quad \forall g \in G, \forall i \in R_{\gamma}, \forall p \in T \\
& \sum_{g} \sum_{k} \sum_{i} \sum_{p} Q_{g k} \cdot X_{i p j t k} Z_{i p j t} \leq S C_{i}, \quad \forall i \in R_{\gamma} \\
& Q_{g k} \geq 0 \text { and integer, } \quad \forall g \in G, \forall k \in K_{\gamma} \\
& X_{i p j t k}, Y_{i p j t}, Z_{i p j t}, A_{i j}, \varphi_{\gamma x} \in\{0,1\}, \quad \forall i, j \in R, \forall p, t \in T, \forall k \in K, \forall \gamma \in C
\end{aligned}
$$

Our objective is to find the GPO structure, $\chi^{*}$, with the minimum cost (10), with the cost of each GPO structure being the sum of the values of the GPOs that compose that structure.

The global cost of each GPO $\gamma$ is obtained through the minimization (11) of the sum of fixed administrative costs (1), fixed (2) and variable (3) transaction costs, acquisition costs (4) and inventory carrying costs (8) of the solution obtained for the corresponding supply chain configuration problem.

Constraints (12) ensure that all paths begin at the network artificial node 00 (located upstream from the producers), and constraints (13) and (14) ensure that, for each path $k$, only one edge arrives at each node $r s$ and only one edge departs from each node $r s$, guaranteeing that paths are formed to serve demand entities.

Constraints (15) ensure flow conservation at the different entities and impose that all demand is satisfied. 
Constraints (16) and (17) impose capacity bundle restrictions: they ensure that all supply capacity (16) and warehouse storage (17) limitations are taken into account. Finally, constraints (18) and (19) define the domains for the decision variables.

\section{Solving the model}

Since we are studying a case with a limited number of hospitals, the optimisation of the GPO structure (module 1) is performed through the computation and comparison of all the costs of the structures under consideration. If we wanted to apply our approach to a case with a significantly larger number of hospital systems, module 1 would have to be modified to avoid determining and comparing the costs of all GPO structures. This could be done by using an algorithm for coalition structure generation. Voice et al. [55] present brief descriptions of several available algorithms for this purpose.

To optimise the supply chain of each GPO (module 2), we use a hybrid algorithm based on Tabu Search (TS) [56,57] and Variable Neighbourhood Search (VNS) [58]. We use a metaheuristic to solve this problem because it is a NP-hard, non-convex mixed-integer, non-linear problem (MINLP). Additionally, we want our tool to be easily adaptable to solve real size problem instances with diverse cost characteristics. Due to their features, metaheuristics are well suited to solve complex cross-functional supply chain management problems [59]. Further details about the construction and parameterization of this algorithm are discussed in Rego and Pinho de Sousa [52], but in this paper, for self-containment reasons, we will only present the main characteristics of the adopted approach.

Our hybrid algorithm combines the search scheme of a Tabu Search, by incorporating a tabu list that forbids repetition of recent moves, with the diversification features of VNS, by changing the neighbourhood structure when the search seems unable to 
improve the current solution. This method provides the flexibility required to cope with a great diversity of problems (e.g., in terms of types and number of entities and/or types of costs and constraints considered), and is suitable to handle a great variety of real life, highly combinatorial situations.

\subsection{Initial solution}

An initial solution is constructed through an iterated creation of network supply paths, until all demand is satisfied. Each path is formed by starting at a point of care unit, and by adding supply or storage edges, until one of the producers is reached. The edge that arrives at the last node in the path is chosen by selecting randomly its node of origin from all possible origins. Feasibility was considered an important requirement, since the constrained nature of the problem may complicate the attainment of a feasible solution during the search. If the demand of the point of care unit cannot be fully fulfilled due to a supply or storage constraint, the path under construction will be valued with the feasible quantity and another path will be constructed for the remaining quantity.

\subsection{Objective function}

The objective function has two components: the original objective function of the problem (see Section 3.3) plus a function P that penalizes infeasibility associated to the limits imposed by storage and supply constraints:

$$
P=\left[\sum_{g} \sum_{k}\left(\text { capacity excess }_{g k} \times \eta_{g}\right)\right] \times \varepsilon,
$$


where:

- capacity excess $g k$ is the sum of the quantities in excess of item $g$ flowing through network supply path $k$ due to storage and supply constraints;

- $\eta_{g}$ is a parameter that adjusts the penalization to the scale of the costs considered (in our algorithm, $\eta_{g}$ is the higher unit price charged by the producers of item $g$ ); and

- $\varepsilon$ is a dynamic parameter (updated every $\kappa$ iterations) that is multiplied (divided) by 2 if the search stays in unfeasible (feasible) regions (in our case, the initial value of $\varepsilon$ is 1 , and $\kappa=10)$.

\subsection{Neighbourhood structures}

Due to the specific characteristics of the costs considered in our model, where the cost of sending a given quantity through one edge depends on the network supply path that quantity travelled before, we could not define the neighbourhood of a solution by employing the most usual and simple moves, such as insertion or swapping of elements. Therefore, we move to a neighbour solution by swapping complete or partial network supply paths, as exemplified in Figure 7, where we highlight two partial paths that could be swapped (ending in $\mathrm{H}_{2}$ ) and two complete paths that could be swapped (ending in $\mathrm{U}_{15}$ ). During the search process we allow some temporary occurrences of infeasible solutions, and follow a best improvement strategy (i.e., the entire neighbourhood is searched). 


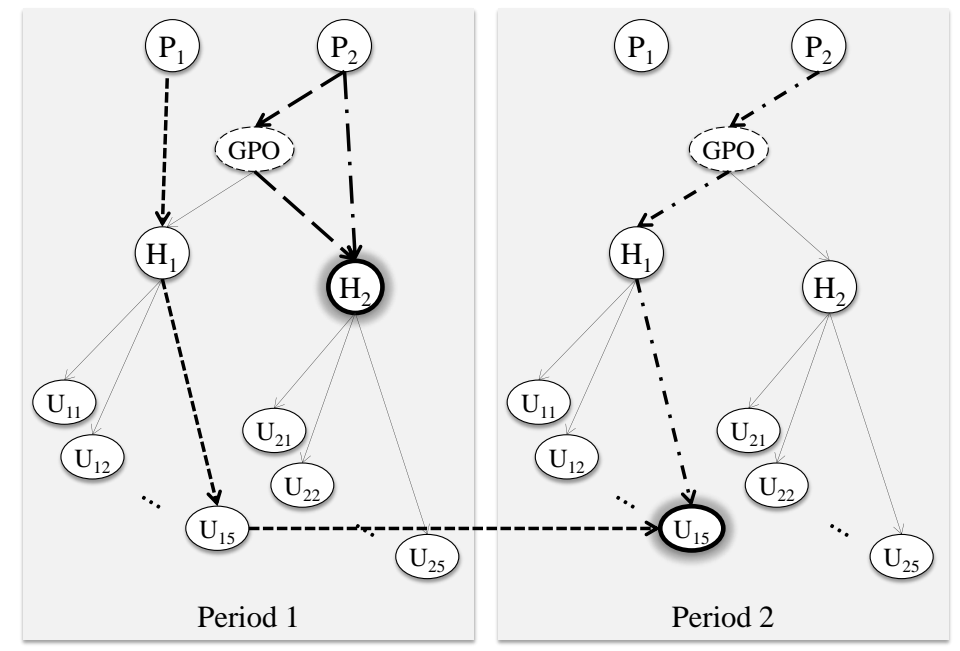

Figure 7 Examples of network supply paths swapping

We developed three neighbourhood structures: two cost based procedures (NS1 and NS2) and a random neighbourhood scheme. We combine all types of moves by running each of these three neighbourhood structures during a given number of iterations, $\mathrm{p}_{\max }$ (in our case, we set $\mathrm{p}_{\max }=500$ ).

NS1 selects the paths with the minimum unit cost, ignoring the current solution structure (i.e., the selection does not take into account the fact that other paths of the current solution may use edges that are common to the path under analysis). NS2 selects the paths with the minimum unit cost, but considering the current solution structure. Finally, the random neighbourhood structure selects a new path by randomly choosing a chain in a way that the capacity constraints are satisfied.

\subsection{Tabu list}

The tabu list stores the last combination edge $\times$ path $\times$ item of a number of recently replaced paths, so that it is not possible to include these edges in the paths that will be tested to form new solutions. The tenure of the tabu list is randomly determined using a uniform distribution - Uniform $[\lambda ; \delta]$, where $\lambda$ is $1 / 3$ of the number of network 
elements, and $\delta$ is the number of network nodes. This way, the tenure of the tabu list is adapted to the size of the supply network of each GPO analysed.

\subsection{Aspiration criterion}

We use an aspiration criterion based on the global objective, by accepting a tabu solution if it yields the best solution ever found, even if it results from a tabu move.

\section{Illustrative example}

Assume that we want to design the GPO (coalition) structure for five potentially cooperating hospitals that intend to purchase two items offered by two competing suppliers, during five purchasing periods. They want to serve the demand of five point of care units per hospital, taking into account the specific features of the supply chains of these hospitals. Since small intensive purchasing groups are more successful when all members have a similar influence and similar objectives [6], we considered that the five hospitals are similar in terms of their size (measured through their demand volumes for both items 1 and 2).

These five hospitals ${ }^{2}$, or subgroups of them, may form virtual/informal GPOs to aggregate demand volumes, thus obtaining lower item prices, and eventually a reduction of other purchasing costs. We have randomly generated demand, costs and constraints, using, as an inspiration, the characteristics of the supply systems of the research case under analysis (e.g., the types of costs). The point of care units were classified as units of high demand or units of low demand, according to a binomial distribution with $\mathrm{p}=$

\footnotetext{
2 A network with 2 suppliers, 1 GPO, 5 hospitals and 5 point of care units per hospital, and a planning horizon of 5 purchasing periods has 165 nodes.
} 
0.5. Demand was determined through a normal distribution: $N(\mu=100, \sigma=20)$ or $\mathrm{N}(\mu=50, \sigma=20)$ for high or low demand, respectively. Costs were generated using the distributions shown in Table 2. The relative values of the various costs are realistic, and the generated demands and suppliers' prices represent well those from real items.

The developed algorithms were implemented in $\mathrm{C}++$ and executed on a PC Intel Core 2 CPU 72002.2 Ghz.

In 30 runs to optimise the grand GPO (i.e., the GPO that aggregates the five hospitals), the hybrid VNS / Tabu Search algorithm took 5 minutes and 19 seconds on average, to perform an average of 7728 iterations to reach the best solution. The average run time (until the activation of the stopping criterion) was 8 minutes and 4 seconds, and the coefficient of variation of the solution values was 0.012 .

To determine how the five hospitals should cooperate, we analysed the outcomes of the 31 possible GPOs (coalitions) they could form. For each GPO, we considered the solution corresponding to the best of 10 runs of the hybrid algorithm. Then, we compared all the 52 possible GPO structures composed from the 31 GPOs, in order to minimise the global costs of the five hospitals. Figure 8 shows the percentage of savings that could be achieved through the 51 different cooperative solutions, when compared to a situation of no cooperation, and Table 4 compares the three best solutions formed by all the five hospitals with a no-cooperation situation. In Table 4, we can also observe that, although the five hospitals have similar sizes in terms of their demand for items 1 and 2, their costs (e.g., average variable unitary cost), when in a no-cooperation situation, are not the same. 
Table 2 Distributions used to generate data ${ }^{3}[52]$

\begin{tabular}{|c|c|c|c|c|c|}
\hline \multirow{6}{*}{$\begin{array}{l}\text { acquisition } \\
\text { cost }\end{array}$} & \multirow{6}{*}{$\begin{array}{c}\text { Base cost } \\
\text { Item1: } \\
\text { Uniform }[100,120] \\
\text { Item } 2: \\
\text { Uniform }[50,70]\end{array}$} & \multicolumn{4}{|c|}{ Quantity discount structure } \\
\hline & & \multicolumn{2}{|c|}{ Order quantity } & \multicolumn{2}{|c|}{ Discount } \\
\hline & & \multicolumn{2}{|c|}{$[0, \mathrm{LS} 1[$} & \multicolumn{2}{|c|}{$0 \%$} \\
\hline & & \multicolumn{2}{|c|}{ [LS1, LS2[ } & \multicolumn{2}{|c|}{ Uniform $[0 \%, 5 \%]$} \\
\hline & & \multicolumn{2}{|c|}{ [LS2, LS3[ } & \multicolumn{2}{|c|}{ Uniform $[5 \%, 10 \%]$} \\
\hline & & \multicolumn{2}{|c|}{$[\mathrm{LS} 3,+\infty[$} & \multicolumn{2}{|c|}{ Uniform $[10 \%, 20 \%]$} \\
\hline $\begin{array}{c}\text { inventory } \\
\text { carrying cost }\end{array}$ & \multicolumn{5}{|c|}{ Uniform [1/1000, 3/1000] } \\
\hline $\begin{array}{l}\text { commercial } \\
\text { margin }\end{array}$ & $\begin{array}{c}\text { producer } \rightarrow G P O \\
\text { Uniform }[-10 \%,-1 \%]\end{array}$ & \multicolumn{2}{|c|}{$\begin{array}{c}\text { producer } \rightarrow \text { care unit } \\
\text { GPO } \rightarrow \text { care unit } \\
\text { hospital } \rightarrow \text { hospital or care } \\
\text { unit of other hospital } \\
\text { Uniform }[5 \%, 10 \%] \\
\end{array}$} & \multicolumn{2}{|c|}{$\begin{array}{c}G P O \rightarrow \text { hospital } \\
\text { hospital } \rightarrow \text { hospital } \\
\text { Uniform }[2 \%, 7 \%]\end{array}$} \\
\hline $\begin{array}{l}\text { fixed } \\
\text { administrative } \\
\text { cost }\end{array}$ & $\begin{array}{c}\text { producer } \rightarrow G P O \\
\text { producer } \rightarrow \text { hospital } \\
G P O \rightarrow \text { hospital } \\
\text { Uniform[1000,1500] }\end{array}$ & \multicolumn{2}{|c|}{$\begin{array}{c}\text { producer } \rightarrow \text { care unit } \\
\text { GPO } \rightarrow \text { care unit } \\
\text { hospital } \rightarrow \text { hospital or care } \\
\text { unit of other hospital } \\
\text { distribution identical to the } \\
\text { one of the hospital where } \\
\text { the care unit belongs }\end{array}$} & \multicolumn{2}{|c|}{$\begin{array}{l}\text { hospital } \rightarrow \text { hospital } \\
\text { Uniform }[500,1000]\end{array}$} \\
\hline $\begin{array}{l}\text { fixed } \\
\text { transaction } \\
\text { cost }\end{array}$ & $\begin{array}{l}\text { producer } \rightarrow G P O \\
\text { producer } \rightarrow \text { hospital } \\
\text { GPO } \rightarrow \text { hospital } \\
\text { hospital } \rightarrow \text { hospital } \\
\text { Uniform }[200,500]\end{array}$ & \multicolumn{2}{|c|}{$\begin{array}{c}\text { producer } \rightarrow \text { care unit } \\
\text { GPO } \rightarrow \text { care unit } \\
\text { hospital } \rightarrow \text { hospital or care } \\
\text { unit of other hospital } \\
\text { distribution identical to the } \\
\text { one of the hospital where } \\
\text { the care unit belongs } \\
\end{array}$} & \multicolumn{2}{|c|}{$\begin{array}{r}\text { hospital } \rightarrow \text { care unit of the same } \\
\text { hospital } \\
\text { care unit } \rightarrow \text { care unit of the same } \\
\text { hospital } \\
\text { Uniform }[10,20]\end{array}$} \\
\hline $\begin{array}{l}\text { variable } \\
\text { transaction } \\
\text { cost }\end{array}$ & $\begin{array}{l}\text { producer } \rightarrow G P O \\
\text { GPO } \rightarrow \text { hospital } \\
\text { hospital } \rightarrow \text { hospital } \\
\text { Uniform }[1,10]\end{array}$ & $\begin{array}{c}\text { producer } \rightarrow \\
\text { hospital } \\
\text { hospital } \rightarrow \\
\text { care unit of } \\
\text { other } \\
\text { hospital } \\
\text { Uniform } \\
{[5,10]} \\
\end{array}$ & $\begin{array}{l}\text { producer } \rightarrow \\
\text { care unit } \\
\text { Uniform } \\
{[10,15]}\end{array}$ & $\begin{array}{l}\mathrm{GPO} \rightarrow \text { care } \\
\quad \text { unit } \\
\text { Uniform }[5,15]\end{array}$ & $\begin{array}{l}\text { hospital } \rightarrow \text { care } \\
\text { unit of the same } \\
\quad \text { hospital } \\
\text { care unit } \rightarrow \text { care } \\
\text { unit of the same } \\
\quad \text { hospital } \\
\text { Uniform }[5,15]\end{array}$ \\
\hline \multicolumn{6}{|c|}{$\begin{array}{l}\text { LS1 }=25 \% \text { of total demand } / \text { no. of periods } \\
\text { LS2 }=50 \% \text { of total demand } / \text { no. of periods } \\
\text { LS3 }=75 \% \text { of total demand } / \text { no. of periods }\end{array}$} \\
\hline
\end{tabular}

One of the advantages of our approach is the possibility of analysing not only the effects (e.g., in terms of costs) of the various cooperating strategies in the network as a whole but also the impact of the global optimisation on each of the hospitals and point of care units. This possibility, making the different impacts visible, is a pre-condition to a fair distribution of cooperation costs and gains, since all participants can analyse in advance the financial consequences, to the group and to the participants, of all possible cooperation arrangements. This will simultaneously determine which hospitals should cooperate when purchasing a specific set of items, according to up to date relevant

\footnotetext{
3 The detailed data sets are available in electronic format upon request.
} 
market conditions. This can also be used to support the negotiation between these participants on how to allocate financial results of that cooperation.

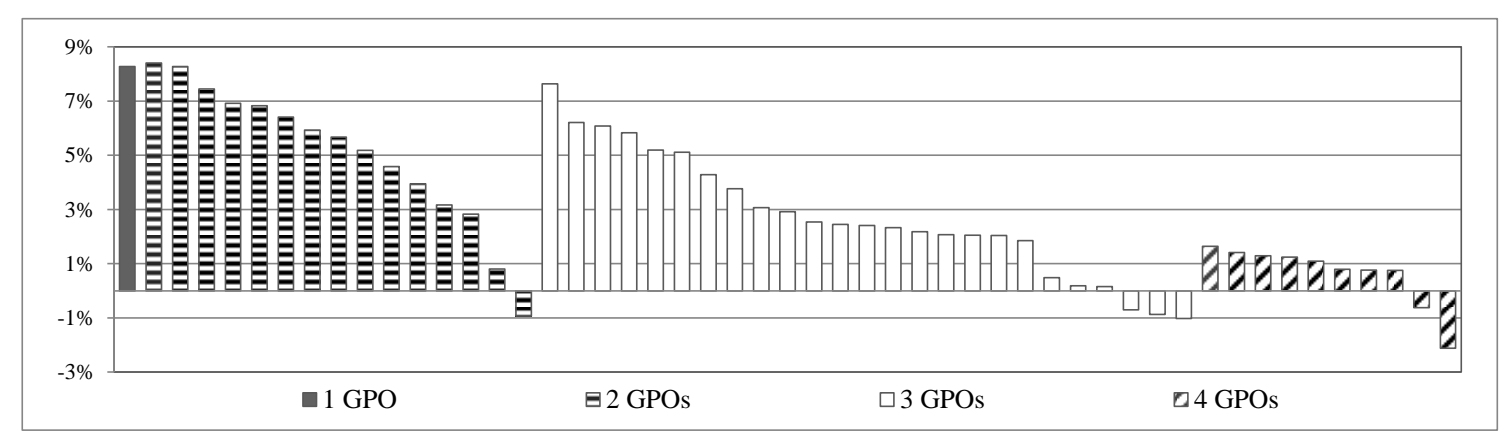

Figure 8 Total cost savings of various cooperative solutions vs. non-cooperative solution

Table 3 Best cooperative vs. non-cooperative solutions

\begin{tabular}{|c|l|r|c|}
\hline \multirow{2}{*}{ Solution } & \multicolumn{1}{|c|}{ Solution description } & \multicolumn{2}{|c|}{ Total Cost } \\
\cline { 3 - 4 } & \multicolumn{1}{|c|}{ Amount } & $\%$ of Savings \\
\hline $\begin{array}{c}\text { Initial } \\
\text { Situation }\end{array}$ & $\begin{array}{l}\text { No cooperation: each of the 5 hospitals has } \\
\text { an isolated purchasing strategy / network: } 4 \\
5,6,7,8\end{array}$ & $2,153,115$ & - \\
\hline $\begin{array}{c}\text { Best } \\
\text { cooperating } \\
\text { solutions }\end{array}$ & $\begin{array}{l}\text { All 5 hospitals cooperating: creation of } 1 \\
\text { SPO, }(1,2,3,4,5)\end{array}$ & $1,974,990$ & $8.27 \%$ \\
& $\begin{array}{l}(1,2,5),(3,4) \quad \Rightarrow 2 \text { GPOs } \\
(1,3,5),(2,4) \quad \Rightarrow 2 \text { GPOs }\end{array}$ & $1,974,770$ & $8.28 \%$ \\
\hline
\end{tabular}

Table 4 Best non-cooperative solutions: comparison of individual hospitals

\begin{tabular}{|c|c|c|c|c|r|r|r|}
\hline \multirow{2}{*}{ Hospital } & \multicolumn{2}{|c|}{ Demand } & \multicolumn{2}{c|}{$\begin{array}{r}\text { Average variable unitary } \\
\text { cost }\end{array}$} & \multirow{2}{*}{$\begin{array}{c}\text { Variable } \\
\text { costs }\end{array}$} & \multirow{2}{*}{ Fixed costs } & \multirow{2}{*}{ Total cost } \\
\cline { 2 - 5 } & Item 1 & Item 2 & Item 1 & \multicolumn{1}{|c|}{ Item 2 } & & & \\
\hline 1 & 1536 & 1664 & 117.26 & 70.03 & 296,639 & 92,060 & 388,699 \\
\hline 2 & 2088 & 1674 & 116.74 & 76.46 & 371,762 & 70,454 & 442,216 \\
\hline 3 & 1769 & 2522 & 121.49 & 78.06 & 411,783 & 83,203 & 494,986 \\
\hline 4 & 1120 & 1910 & 121.70 & 80.00 & 289,112 & 92,146 & 381,258 \\
\hline 5 & 1832 & 1767 & 118.99 & 77.93 & 355,680 & 90,277 & 445,957 \\
\hline Total & - & - & - & - & $1,724,975$ & 428,140 & $2,153,115$ \\
\hline
\end{tabular}

Table 5 and Table 6 present the costs of the best cooperative solution: hospitals 1, 3 and 5, forming a purchasing group; and hospitals 2 and 4, forming another group. The fixed costs of these purchasing groups have not been allocated to individual hospitals as that distribution would imply the application of some subjective distribution criterion. In a real negotiation process, hospitals can decide which criteria to use. We can observe, in the example, the various impacts of cooperation on individual hospitals: see, for 
example, the average variable unitary cost of the hospitals within each purchasing group (Table 5). Similarly, we also have different percentages of reduction in variable costs.

The information provided by the model should then be used by the five hospitals to decide how to allocate the financial results of their cooperation effort. For example, given the intentions to cooperate expressed by the five hospitals, and as a consequence of the results obtained, a negotiation may be initiated between groups $(2,4)$ and $(1,3,5)$ aiming at implementing a solution where all five hospitals cooperate (with $8.27 \%$ savings instead of the global $8.41 \%$ of the optimal solution). In this situation, hospitals 2 and 4 may accept to transfer part of their savings to hospitals 1, 3, and 5, as long as they obtain a result that overcomes the $2.0 \%$ savings that they would attain if they stayed isolated in a group (see Table 6). Alternatively, the five hospitals may decide to organize their purchases through the two GPOs recommended in the optimal solution, thus maximizing their global savings, and simultaneously implement a share scheme that involves the transferral of some of the resulting financial gains from $(1,3,5)$ to $(2$, $4)$.

It must be noted that the perception of fairness for the allocation of gains of a collaboration by the parties involved often involves some subjective elements and may be quite dependent on the situation under analysis (e.g., on the distribution of power among parties) [60].

Table 5 Best cooperative vs. best non-cooperative solutions: comparison of average variable unitary costs

\begin{tabular}{|c|c|c|c|c|c|c|c|}
\hline \multirow{3}{*}{$\begin{array}{c}\text { Purchasing } \\
\text { groups }\end{array}$} & \multirow{2}{*}{ Hospital } & \multicolumn{6}{|c|}{ Average variable unitary costs } \\
\cline { 3 - 8 } & & $\begin{array}{c}\text { No } \\
\text { cooperation }\end{array}$ & Cooperation & $\begin{array}{c}\text { Reduction } \\
(\%)\end{array}$ & $\begin{array}{c}\text { No } \\
\text { cooperation }\end{array}$ & Cooperation & $\begin{array}{c}\text { Reduction } \\
(\%)\end{array}$ \\
\hline & 1 & 117.26 & 96.67 & $17.6 \%$ & 70.03 & 59.59 & $14.9 \%$ \\
\cline { 2 - 8 } & 2 & 116.74 & 98.67 & $15.5 \%$ & 76.46 & 60.26 & $21.2 \%$ \\
\cline { 2 - 8 }$(1,2,3,4,5)$ & 3 & 121.49 & 97.30 & $19.9 \%$ & 78.06 & 57.95 & $25.8 \%$ \\
\cline { 2 - 8 } & 4 & 121.7 & 99.95 & $17.9 \%$ & 80 & 59.54 & $25.6 \%$ \\
\cline { 2 - 8 } & 5 & 118.99 & 97.15 & $18.4 \%$ & 77.93 & 60.03 & $23.0 \%$ \\
\hline \multirow{3}{*}{$(1,3,5)$} & 1 & 117.26 & 97.25 & $17.1 \%$ & 70.03 & 68.84 & $1.7 \%$ \\
\cline { 2 - 8 } & 3 & 121.49 & 99.21 & $18.3 \%$ & 78.06 & 69.48 & $11.0 \%$ \\
\hline \multirow{2}{*}{$(2,4)$} & 5 & 118.99 & 101.12 & $15.0 \%$ & 77.93 & 67.77 & $13.0 \%$ \\
\cline { 2 - 8 } & 2 & 116.74 & 115.37 & $1.2 \%$ & 76.46 & 73.44 & $4.0 \%$ \\
\hline
\end{tabular}


Table 6 Best cooperative vs. best non-cooperative solutions: comparison of costs

\begin{tabular}{|c|c|c|c|c|c|c|c|c|c|c|}
\hline \multirow{2}{*}{$\begin{array}{l}\text { Purchasing } \\
\text { groups }\end{array}$} & \multirow[b]{2}{*}{ Hospital } & \multicolumn{3}{|c|}{ Variable costs } & \multicolumn{3}{|c|}{ Fixed costs } & \multicolumn{3}{|c|}{ Total costs } \\
\hline & & \begin{tabular}{c|} 
No \\
cooperation
\end{tabular} & Cooperation & $\begin{array}{c}\text { Reduction } \\
(\%)\end{array}$ & $\begin{array}{c}\text { No } \\
\text { cooperation } \\
\end{array}$ & Cooperation & $\begin{array}{c}\text { Reduction } \\
(\%)\end{array}$ & \begin{tabular}{c|} 
No \\
cooperation
\end{tabular} & Cooperation & $\begin{array}{c}\text { Reduction } \\
(\%)\end{array}$ \\
\hline \multirow{5}{*}{$(1,2,3,4,5)$} & 1 & \begin{tabular}{|r|}
296,639 \\
\end{tabular} & 247,633 & $16.5 \%$ & \multirow{6}{*}{428,141} & \multirow{6}{*}{592,500} & \multirow{6}{*}{$-38.4 \%$} & 388,699 & \multirow{6}{*}{$1,974,990$} & \multirow{6}{*}{$8.27 \%$} \\
\hline & 2 & 371,762 & 306,889 & $17.5 \%$ & & & & 442,216 & & \\
\hline & 3 & $\begin{array}{l}411,783 \\
\end{array}$ & 318,267 & $22.7 \%$ & & & & 494,986 & & \\
\hline & 4 & 289,112 & 225,657 & $21.9 \%$ & & & & 381,258 & & \\
\hline & 5 & 355,680 & 284,044 & $20.1 \%$ & & & & 445,957 & & \\
\hline \multicolumn{2}{|c|}{ Total } & $1,724,975$ & $1,382,490$ & $19.85 \%$ & & & & 2.153 .116 & & \\
\hline \multirow{3}{*}{$(1,3,5)$} & 1 & 296,639 & 263,929 & $11.0 \%$ & 92,060 & \multirow{3}{*}{245,451} & \multirow{3}{*}{$7.6 \%$} & 388,699 & \multirow{3}{*}{$1,165,120$} & \multirow{3}{*}{$12.37 \%$} \\
\hline & 3 & 411,783 & 350,730 & $14.8 \%$ & 83,203 & & & 494,986 & & \\
\hline & 5 & 355,680 & 305,010 & $14.2 \%$ & 90,277 & & & 445,957 & & \\
\hline \multirow{2}{*}{$(2,4)$} & 2 & 371,762 & 363,826 & $2.1 \%$ & 70,454 & \multirow{2}{*}{172,780} & \multirow{2}{*}{$-6.3 \%$} & 442,216 & \multirow{2}{*}{806,921} & \multirow{2}{*}{$2.01 \%$} \\
\hline & 4 & 289,112 & 270,315 & $6.5 \%$ & 92,146 & & & 381,258 & & \\
\hline \multicolumn{2}{|c|}{ Total } & $1,724,975$ & $1,553,810$ & $9.9 \%$ & 428,141 & 418,231 & $2.3 \%$ & $2,153,116$ & $1,972,041$ & $8.41 \%$ \\
\hline
\end{tabular}

A comprehensive sensitivity analysis revealed that the algorithm operates as expected. As an example, it is interesting to analyse the effect on the total cost of the possible GPOs (see Figure 9), and on the final cooperative solution (see Figure 10) of the changes experimented in two of the cooperation related variables - the fixed administrative costs of establishing a commercial relation $\left(a_{i j}\right)$, and the quantity discounts offered by the suppliers $\left(w_{g l j}\right)$.

When the fixed administrative cost increases, the total cost of the various possible GPOs rises (see Figure 9), as expected. In this situation, there will be a higher incentive to cooperate, because joint solutions allow the GPO members to engage in less commercial relations. This was what happened in the GPO structure solution: when the fixed administrative cost is higher, the solution recommended by our approach corresponds to the grand GPO (see Figure 10).

When the quantity discounts increase, if the required item quantity volumes are attained, prices decrease and subsequent commercial margins and inventory costs do also decrease. As a consequence, as expected, the total cost of the various possible GPOs decreases (see Figure 9). We can observe that larger GPOs take a better advantage of this situation than small GPOs (e.g., on average, a rise of $10 \%$ in the quantity discounts decreases the grand GPO total cost by approximately $3 \%$, while the total cost of a GPO 
formed by two hospitals will only decrease approximately $2 \%$ ). Additionally, there will be a higher incentive to cooperate, since the consolidation of purchased volumes will enable GPOs to access prices that are lower than they were before, and only larger GPOs can purchase the quantity needed to reach the better prices. When the quantity discounts are higher, the solution recommended by our approach is, as expected, the grand GPO (see Figure 10).

We must recall that our work assumes that the involved GPOs are informally structured programmes, and consequently, in this illustrative example, larger GPOs are not hindered by rising GPO coordination costs associated with GPO size. The results obtained are, therefore, in accordance with the characteristics of the modelled situation. In other contexts, if much larger and formal GPOs were involved, we could have a different behaviour as the observed direct relation between higher fixed administrative costs and higher quantity discounts and cooperation could be counterbalanced by the impact of a rise on GPO coordination and operation costs. Our approach can, however, be easily adapted to analyse problems with different cost structures. 


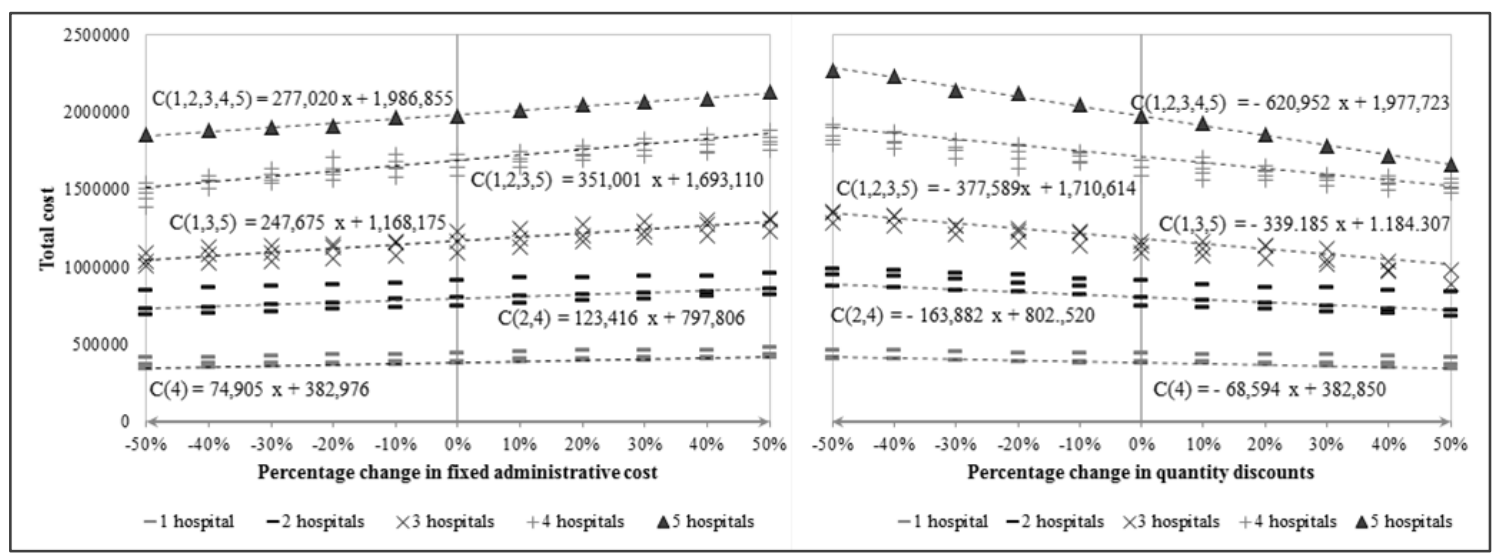

Figure 9 Sensitivity analysis: GPOs total cost

\begin{tabular}{|c|c|c|c|c|c|c|c|c|c|c|c|}
\hline & $-50 \%$ & $-40 \%$ & $-30 \%$ & $-20 \%$ & $-10 \%$ & & $10 \%$ & $20 \%$ & $30 \%$ & $40 \%$ & $50 \%$ \\
\hline & \multicolumn{11}{|c|}{ Percentage change in fixed administrative cost } \\
\hline Best solution & $(2,3,4,5),(1)$ & \multicolumn{2}{|c|}{$(1,3,5),(2,4)$} & \multicolumn{2}{|c|}{$(1,2,5),(3,4)$} & \multicolumn{4}{|c|}{$(1,3,5),(2,4)$} & \multicolumn{2}{|c|}{$(1,2,3,4,5)$} \\
\hline 2nd best & $(1,3,5),(2,4)$ & \multicolumn{2}{|c|}{$(1,2,5),(3,4)$} & \multicolumn{2}{|c|}{$(1,3,5),(2,4)$} & \multicolumn{2}{|c|}{$(1,2,5),(3,4)$} & \multicolumn{2}{|c|}{$(1,2,3,4,5)$} & $(1,3,5),(2$, & $1,2,5),(3,4)$ \\
\hline $\begin{array}{l}\text { Savings relative to } \\
\text { NO cooperation (\%) }\end{array}$ & $13.0 \%$ & $10.8 \%$ & $11.1 \%$ & $11.1 \%$ & $11.0 \%$ & $8.4 \%$ & $9.1 \%$ & $9.4 \%$ & $9.2 \%$ & $8.5 \%$ & $8.4 \%$ \\
\hline \multirow[t]{2}{*}{ Total cost change (\%) } & $-10.8 \%$ & $-7.5 \%$ & $-6.1 \%$ & $-4.8 \%$ & $-3.8 \%$ & & $1.4 \%$ & $2.6 \%$ & $4.2 \%$ & $6.1 \%$ & $8.3 \%$ \\
\hline & \multicolumn{11}{|c|}{ Percentage change in quantity discount } \\
\hline Best solution & $(1,3,5)$ & $(2,4)$ & $(1,4,5),(2,3)$ & $(1,3,5),(2,4)$ & $(1,2,5),(3,4)$ & $(1,3,5),(2,4)$ & $(1,2,5),(3,4)$ & \multicolumn{4}{|c|}{$(1,2,3,4,5)$} \\
\hline 2nd best & $(1,4,5),(2,3)$ & $1,2,5),(3,4)$ & $(1,3,5),(2,4)$ & $(1,4,5),(2,3)$ & $(1,3,5),(2,4)$ & $(1,2,5),(3,4)$ & $(1,2,3,4,5)$ & \multicolumn{4}{|c|}{$(1,2,5),(3,4)$} \\
\hline $\begin{array}{l}\text { Savings relative to } \\
\text { NO cooperation (\%) }\end{array}$ & $6.3 \%$ & $5.8 \%$ & $9.3 \%$ & $7.4 \%$ & $7.6 \%$ & $8.4 \%$ & $11.2 \%$ & $11.2 \%$ & $13.0 \%$ & $14.2 \%$ & $15.2 \%$ \\
\hline Total cost change (\%) & $13.4 \%$ & $11.3 \%$ & $5.2 \%$ & $5.7 \%$ & $3.4 \%$ & & $-0.7 \%$ & $-5.6 \%$ & $-9.6 \%$ & $-12.8 \%$ & $-15.8 \%$ \\
\hline
\end{tabular}

Figure 10 Sensitivity analysis: GPO structure solution

\section{Conclusion}

The approach proposed in this paper can be quite useful in supporting the design and evaluation of alternative cooperative purchasing strategies for healthcare supply chains.

Given the combinatorial nature of the problem and the dimension of real life instances, we have designed a computational procedure based on metaheuristics. Moreover, the flexibility of the approach allows its application to purchasing groups with quite different characteristics, namely in order to perform experiences concerning the optimal size of purchasing groups under different operative and market circumstances, and involving supply chains with different topologies and atypical cost characteristics.

The approach can also be used to promote and facilitate the cooperation process, since it is easily applicable, and it makes the financial impact of the various cooperation 
alternatives transparent, opening way to negotiation processes concerning the allocation of the costs and gains of cooperation between the participating hospitals.

Preliminary computational experiments show the potential of the developed approach in solving quite different cooperative purchasing problems. These experiments have been designed for illustrative purposes, but we believe that the future incorporation of these tools in a Decision Support System can significantly contribute to an increase of healthcare supply chains efficiency and encourage the establishment of cooperative partnerships between their members.

\section{Acknowledgments}

This work is partially financed by the ERDF - European Regional Development Fund, through the COMPETE Programme (operational programme for competitiveness) and by National Funds through FCT - Fundação para a Ciência e a Tecnologia (Portuguese Foundation for Science and Technology) within the project Flexible Design of Networked Engineering Systems (PTDC/SEN-ENR/101802/2008).

\section{References}

1. INE (2010) Conta Satélite da Saúde 2000 - 2008. INE (Instituto Nacional de Estatística / Statistics Portugal), Lisboa

2. OECD (2013) OECD Health Data 2013. OECD, Paris

3. INFARMED (2012) Análise do Mercado de Medicamentos no âmbito do Serviço Nacional de Saúde, em Meio Hospitalar (CHNM) - Novembro. Observatório do Medicamento e Produtos de Saúde, Direcção de Economia do Medicamento e Produtos de Saúde, INFARMED - Autoridade Nacional do Medicamento e Produtos de Saúde, I.P., Lisboa

4. Burns LR, Lee JA (2008) Hospital purchasing alliances: Utilization, services, and performance. Health Care Manag Rev 33 (3):203-215. doi:http://dx.doi.org/10.1097/01.HMR.0000324906.04025.33

5. Monczka RM, Handfield RB, Giunipero LC, Patterson JL, Waters D (2010) Purchasing \& Supply Chain Management. Cengage Learning EMEA, Hampshire, United Kingdom

6. Schotanus F, Telgen J, Boer Ld (2010) Critical success factors for managing purchasing groups. J Purch Supply Manag 16 (1):51-60. doi:http://dx.doi.org/10.1016/j.pursup.2009.10.002

7. Schotanus F (2007) Horizontal Cooperative Purchasing. University of Twente, Enschede, the Netherlands

8. Schoenherr T, Modi SB, Benton WC, Carter CR, Choi TY, Larson PD, Leenders MR, Mabert VA, Narasimhan R, Wagner SM (2012) Research opportunities in purchasing and supply management. Int J Prod Res 50 (16):4556-4579. doi:http://dx.doi.org/10.1080/00207543.2011.613870 
9. Walker H, Schotanus F, Bakker E, Harland C (2013) Collaborative Procurement: A Relational View of BuyerBuyer Relationships. Publ Admin Rev 73 (4):588-598. doi:http://dx.doi.org/10.1111/puar.12048

10. Schotanus F, Telgen J (2007) Developing a typology of organisational forms of cooperative purchasing. J Purch Supply Manag 13 (1):53-68. doi:http://dx.doi.org/10.1016/j.pursup.2007.03.002

11. Bakker E, Walker H, Schotanus F, Harland C (2008) Choosing an organisational form: the case of collaborative procurement initiatives. Int J Procure Manag 1 (3):297-317. doi:http://dx.doi.org/10.1504/IJPM.2008.017527

12. Essig M (2000) Purchasing consortia as symbiotic relationships: developing the concept of "consortium sourcing". Eur J Purch Supply Manag 6 (1):13-22. doi:http://dx.doi.org/10.1016/S0969-7012(99)00031-3

13. Ellison SF, Snyder CM (2011) Countervailing power in wholesale pharmaceuticals. J Ind Econ 58 (1):32-53. doi:http://dx.doi.org/10.1111/j.1467-6451.2010.00408.x

14. Scanlon WJ (2002) Group Purchasing Organizations: Pilot Study Suggests Large Buying Groups Do Not Always Offer Hospitals Lower Prices. GAO - United States General Accounting Office:Testimony Before the Subcommittee on Antitrust, Competition, and Business and Consumer Rights, Committee on the Judiciary, U.S. Senate, Whashington DC

15. Hu Q, Schwarz LB (2011) Controversial Role of GPOs in Healthcare-Product Supply Chains. Prod Oper Manag 20 (1):1-15. doi:http://dx.doi.org/10.1111/j.1937-5956.2010.01121.x

16. Johnson PF (1999) The Pattern of Evolution in Public Sector Purchasing Consortia. Int J Logist Res Appl 2 (1):57 - 73. doi:http://dx.doi.org/10.1080/13675569908901572

17. Schneller ES (2009) The Value of Group Purchasing-2009: Meeting the Needs for Strategic Savings. Health Care Sector Advances, Inc., Arizona

18. Tella E, Virolainen V-M (2005) Motives behind purchasing consortia. Int J Prod Econ 93-94 (0):161-168. doi:http://dx.doi.org/10.1016/j.ijpe.2004.06.014

19. Huff-Rousselle M (2012) The logical underpinnings and benefits of pooled pharmaceutical procurement: A pragmatic role for our public institutions? Soc Sci Med 75 (9):1572-1580. doi:http://dx.doi.org/10.1016/j.socscimed.2012.05.044

20. Nollet J, Beaulieu M (2005) Should an organisation join a purchasing group? Supply Chain Manag Int J 10 (1):11-17. doi:http://dx.doi.org/10.1108/13598540510578333

21. Schneller ES (2000) The Value of Group Purchasing in the Health Care Supply Chain. School of Health Administration and Policy, Arizona State University College of Business, Tempe

22. Laing A, Cotton S (1997) Patterns of inter-organizational purchasing: Evolution of consortia-based purchasing amongst GP fundholders. Eur J Purch Supply Manag 3 (2):83-91. doi:http://dx.doi.org/10.1016/S09697012(96)00020-2

23. Dimitri N, Dini F, Piga G (2006) When should procurement be centralized? In: Dimitri N, Piga G, Spagnolo G (eds) Handbook of Procurement. Cambridge University Press, Cambridge, pp 47-81. doi:http://dx.doi.org/10.1017/CBO9780511492556.004

24. Herzlinger RE (2006) Why innovation in health care is so hard. Harv Bus Rev 84 (5):58

25. Blair RD, Durrance CP (2013) Group Purchasing Organizations, Monopsony, and Antitrust Policy. Managerial and Decision Economics in print. doi:http://dx.doi.org/www.10.1002/mde.2633

26. Sethi SP (2006) Group purchasing organizations: An evaluation of their effectiveness in providing services to hospitals and their patients. International Center for Corporate Accountability (ICCA), New York

27. Bahinipati BK, Kanda A, Deshmukh SG (2009) Coordinated supply management: review, insights, and limitations. Int J Logist Res Appl 12 (6):407-422. doi:http://dx.doi.org/10.1080/13675560802476382

28. Arshinder, Kanda A, Deshmukh SG (2008) Supply chain coordination: Perspectives, empirical studies and research directions. Int J Prod Econ 115 (2):316-335. doi:http://dx.doi.org/10.1016/j.ijpe.2008.05.011

29. Meca A, Timmer J (2008) Supply chain collaboration. In: Kordic V (ed) Supply Chain, Theory and Applications. I-Tech Education and Publishing, Vienna, Austria, pp 1-18

30. Drechsel J (2010) Cooperation in Supply Chains. In: Cooperative Lot Sizing Games in Supply Chains, vol 644. Lecture Notes in Economics and Mathematical Systems. Springer, Berlin, Heidelberg, pp 55-61. doi:http://dx.doi.org/10.1007/978-3-642-13725-9_4

31. DeScioli DT (2005) Differentiating the Hospital Supply Chain for Enhanced Performance. Massachusetts Institute of Technology, Boston

32. Bhakoo V, Singh P, Sohal A (2012) Collaborative management of inventory in Australian hospital supply chains: practices and issues. Supply Chain Manag Int J 17 (2):217-230. doi:http://dx.doi.org/10.1108/13598541211212933

33. Pasin F, Jobim M, Cordeau J (2002) An application of simulation to analyse resource sharing among health-care organisations. Int J Oper Prod Res 22 (4):381 - 393. doi:http://dx.doi.org/10.1108/01443570210420395

34. Beaulieu M, Patenaude G (2004) La gestion des approvisionnements en réseau: le cas du Centre hospitalier Notre-Dame de la Merci. Logistique \& Management Numéro spécial (Logistique Hospitalière):59-64

35. Bhakoo V, Chan C (2011) Collaborative implementation of e-business processes within the health-care supply chain: the Monash Pharmacy Project. Supply Chain Manag Int J 16 (3):184-193. doi:http://dx.doi.org/10.1108/13598541111127173

36. Wang Y, Lai F, Vespa P (2010) Enabling technologies facilitate new healthcare delivery models for acute stroke. Stroke 41 (6):1076-1078. doi:http://dx.doi.org/10.1161/STROKEAHA.110.587261

37. Kodner DL, Spreeuwenberg C (2002) Integrated care: meaning, logic, applications, and implications - a discussion paper. Int J Integr Care 2 (1):1-6

38. Bazzoli GJ, Dynan L, Burns LR, Yap C (2004) Two decades of organizational change in health care: what have we learned? Med Care Res Rev 61 (3):247. doi:http://dx.doi.org/10.1177/1077558704266818 
39. Burns LR, Pauly MV (2002) Integrated Delivery Networks: A detour on the road to integrated health care? Health Aff 21 (4):128 - 143. doi:http://dx.doi.org/10.1377/hlthaff.21.4.128

40. Boonstra A, Govers MJG (2009) Understanding ERP system implementation in a hospital by analysing stakeholders. New Tech Work Employ 24 (2):177-193. doi:http://dx.doi.org/10.1111/j.1468-005X.2009.00227.x

41. Ford EW, Wells R, Bailey B (2004) Sustainable Network Advantages: A Game Theoretic Approach to Community-Based Health Care Coalitions. Health Care Manag Rev 29 (2):159-169. doi:http://dx.doi.org/10.1097/00004010-200404000-00009

42. More E, McGrath M (2002) An Australian case in e-health communication and change. J Manag Dev 21 (8):621632. doi:http://dx.doi.org/10.1108/02621710210437590

43. De Vries G, Bertrand JWM, Vissers JMH (1999) Design requirements for health care production control systems. Prod Plann Contr 10 (6):559 - 569. doi:http://dx.doi.org/10.1080/095372899232858

44. Schneller ES, Smeltzer LR (2006) Strategic Management of the Health Care Supply Chain. Jossey-Bass, San Francisco

45. van Donk DP (2003) Redesigning the supply of gasses in a hospital. J Purch Supply Manag 9 (5-6):225-233. doi:http://dx.doi.org/10.1016/j.pursup.2003.09.008

46. D'Aunno T, Zuckerman H (1987) The Emergence of Hospital Federations: An Integration of Perspectives from Organizational Theory. Med Care Res Rev 2 (44):323-343. doi:http://dx.doi.org/10.1177/107755878704400206

47. Nollet J, Beaulieu M (2003) The development of group purchasing: an empirical study in the healthcare sector. J Purch Supply Manag 9 (1):3-10. doi:http://dx.doi.org/10.1016/S0969-7012(02)00034-5

48. van Weele AJ (2009) Purchasing and Supply Chain Management: Analysis, Strategy, Planning and Practice. 5th edn. Cengage Learning EMEA, Hampshire, United Kingdom

49. Myerson RB (2004) Game Theory - Analysis of Conflict. Harvard University Press, Cambridge, Massachusetts

50. Nash JF (1953) Two-Person Cooperative Games. Econometrica 21 (1):128-140. doi:http://dx.doi.org/10.2307/1906951

51. Sandholm T, Larson K, Andersson M, Shehory O, Tohmé F (1999) Coalition structure generation with worst case guarantees. Artif Intell 111 (1-2):209-238. doi:http://dx.doi.org/10.1016/S0004-3702(99)00036-3

52. Rego N, Pinho de Sousa J (2009) Supporting the Definition of Strategies for the Configuration of Health Care Supply Chains. In: Voss S, Pahl J, Schwarze S (eds) Logistik Management - Systeme, Methoden, Integration, Proceedings of LM'09, Hamburg, 2nd-4th September. Physica-Verlag, Berlin, Heidelberg, pp 435-456. doi:http://dx.doi.org/10.1007/978-3-7908-2362-2 22

53. Ahuja RK, Magnanti TL, Orlin JB (1993) Network flows - theory, algorithms and applications. Prentice Hall, New Jersey

54. Muriel A, Simchi-Levi D (2003) Supply Chain Design and Planning - Applications of Optimization Techniques for Strategic and Tactical Models. In: Kok AG, Graves SC (eds) Supply Chain Management: Design, Coordination and Operation, vol 11. Elsevier, Amsterdam, pp 17-94. doi:http://dx.doi.org/10.1016/S0927-0507(03)11002-X

55. Voice T, Polukarov M, Jennings NR (2012) Coalition structure generation over graphs. J Artif Intell Res 45 (1):165-196. doi:http://dx.doi.org/10.1613/jair.3715

56. Glover F (1989) Tabu Search - Part I. ORSA J Comput 1 (3):190-206. doi:http://dx.doi.org/10.1287/ijoc.1.3.190

57. Glover F (1990) Tabu Search - Part II. ORSA J Comput 2 (1):4-32. doi:http://dx.doi.org/10.1287/ijoc.2.1.4

58. Mladenovic N, Hansen P (1997) Variable neighborhood search. Comput Oper Res 24 (11):1097-1100. doi:http://dx.doi.org/10.1016/S0305-0548(97)00031-2

59. Griffis SE, Bell JE, Closs DJ (2012) Metaheuristics in Logistics and Supply Chain Management. J Bus Log 33 (2):90-106. doi:http://dx.doi.org/10.1111/j.0000-0000.2012.01042.x

60. Stadtler H (2009) A framework for collaborative planning and state-of-the-art. OR Spectrum 31 (1):5-30. doi:http://dx.doi.org/10.1007/s00291-007-0104-5 